\title{
Chronic Leukemia in Remission
}

National Cancer Institute

\section{Source}

National Cancer Institute. Chronic Leukemia in Remission. NCI Thesaurus. Code C4898.

Leukemia that is no longer growing or metastasizing; it is responding to therapy. 